\title{
Overall impact of outpatient stress cardiac magnetic resonance (CMR) imaging on clinical care is independent of appropriate use criteria
}

\author{
Sloane A McGraw", Omer Mirza', Vibhav Rangarajan', Satish J Chacko1, Michael A Bauml', Afshin Farzaneh-Far ${ }^{1,2}$ \\ From 19th Annual SCMR Scientific Sessions \\ Los Angeles, CA, USA. 27-30 January 2016
}

\section{Background}

Stress cardiac-magnetic-resonance (CMR) imaging can provide important diagnostic and prognostic information in patients with known or suspected coronary artery disease. However, given the rising costs of imaging, there is increasing pressure to provide evidence for direct additive impact on clinical care. Appropriate use criteria (AUC) have been developed by professional organizations as a response to rising costs, with the goal of optimizing test-patient selection. Consequently, the AUC are now increasingly used by third-party-payers to assess reimbursement. However, these criteria were created by expert consensus with limited systematic validation. The aim of this study was to determine whether the AUC can predict rates of active change in clinical care resulting from stress CMR.

\section{Methods}

305 consecutive outpatients referred from cardiology clinic for stress CMR were prospectively enrolled at a U.S. university teaching hospital. Definitions for "active change in clinical care" due to stress CMR were predefined and classified by two cardiologists directly from medical records and/or from patients. Categories included: coronary angiography, revascularization, preoperative clearance, medication change, subspecialty referral, ordering of additional diagnostic testing, and discharge from cardiology clinic. Tests were classified as "appropriate", "may be appropriate" or "rarely appropriate" according to the "2013 Multimodality Appropriate Use Criteria for the Detection and Risk Assessment of Stable Ischemic Heart Disease."

\section{Results}

Overall, stress CMR led to an active change in clinical care in $67 \%$ of patients. This included initiation of invasive management in $14 \%$ of cases, and non-invasive changes in $60 \%$ (Figure 1). Stress CMR results directly led to coronary angiography in $14 \%$, revascularization in $5 \%$, pre-operative clearance in $12 \%$, medication change in $18 \%$, subspecialty referral in $9 \%$, ordering of additional diagnostic testing in $9 \%$, and discharge from cardiology clinic in $18 \%$. Rates of active change in clinical care did not vary significantly across AUC categories $(\mathrm{p}=0.732)$ (Figure 2).

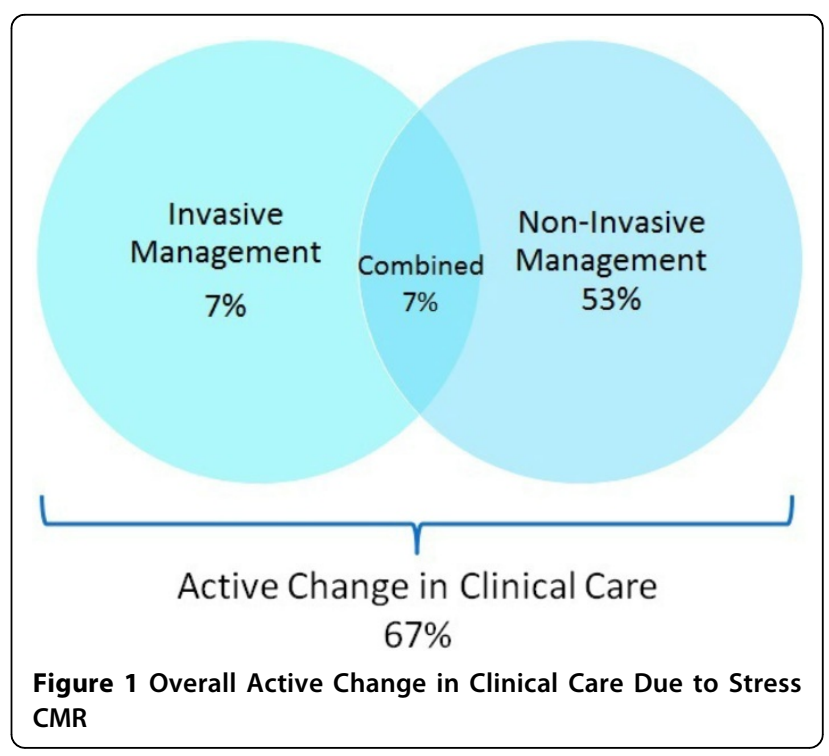

${ }^{1}$ Cardiology, University of Illinois- Chicago, Chicago, IL, USA

Full list of author information is available at the end of the article 


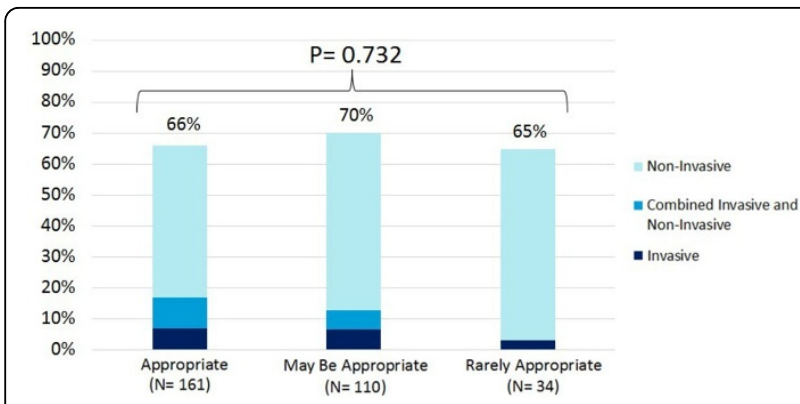

Figure 2 Active Change in Clinical Care Based on AUC Classification

\section{Conclusions}

Stress CMR made a significant clinical impact on management, resulting in active change in clinical care in $67 \%$ of patients, with the majority of changes being non-invasive. However, overall rates of active change in clinical care were similar across AUC categories $(p=0.732)$. This suggests that consideration should be given to upgrading some of the "rarely appropriate" indications to either "may be appropriate" or "appropriate" classifications.

\section{Authors' details}

${ }^{1}$ Cardiology, University of Illinois- Chicago, Chicago, IL, USA. ${ }^{2}$ Cardiology,

Duke University, Durham, NC, USA.

Published: 27 January 2016

Cite this article as: McGraw et al:: Overall impact of outpatient stress cardiac magnetic resonance (CMR) imaging on clinical care is

independent of appropriate use criteria. Journal of Cardiovascular Magnetic Resonance 2016 18(Suppl 1):Q20.

Submit your next manuscript to BioMed Central and take full advantage of:

- Convenient online submission

- Thorough peer review

- No space constraints or color figure charges

- Immediate publication on acceptance

- Inclusion in PubMed, CAS, Scopus and Google Scholar

- Research which is freely available for redistribution

Submit your manuscript at www.biomedcentral.com/submit 